\title{
Optimizing service life of conveyor belts while transporting bulk load
}

\author{
Vitalii Monastyrskyi ${ }^{1}$, Serhii Monastyrskyi ${ }^{1}$, and Borys Mostovyi ${ }^{1, *}$ \\ ${ }^{1}$ Institute of Geotechnical Mechanics named by N. Poljakov of National Academy of Sciences of \\ Ukraine, 49005, Dnipro, Simferopolska Str., 2a, Ukraine
}

\begin{abstract}
The paper considers problems concerning optimization of service life of a conveyor belt in terms of its bulk material loading. Statement of the problem of belt life optimization is in the determining minimum of difference between squared velocity of a conveyor belt and projection of horizontal component of the load velocity when it contacts a belt onto the belt motion plane. The problem was solved numerically taking into consideration the objective function, varied parameters, and their limitation. Cases of direct-flow loading and loading with the help of special devices with straight and curved trough profiles have been analyzed. Regularities of changes in the belt service life due to significant factors in terms of direct-flow loading and loading with special device have been obtained to perform comparative analysis of different variants in terms of similar value of the objective function. The variants with maximum belt life and minimum objective function have been selected. For short conveyors, in terms of direct-flow loading, belt life decreases by 1.5-2.0 times comparing to the use of a loading device, and in terms of long conveyors, it decreases by 5-6 times, if value of the objective function is $0.5-1.0 \mathrm{~m}^{2} / \mathrm{s}^{2}$.
\end{abstract}

\section{Introduction}

Analysis of the operation of conveyors transporting bulk load has demonstrated that the service life of a belt depends on numerous factors: operational conditions, quality of the belts being used, structure of loading devices, physical and mechanical properties of the load, uniformity of its supply, and climatic conditions. Determining the reasons for conveyor belt wear [1-5] aimed at its further elimination is the basic task while solving general problem of improving reliability and performability of belt conveyors. Complexity of the task is in the fact that many factors among the indicated ones are in weak correlation with the parameters of both belt and conveyor preventing from developing adequate mathematical model of the optimization of conveyor belt service life. Paper [6] substantiates and solves the problem of conveyor belt wear under the effect of bulk load in the probability form. In this context, it has been adopted that a conveyor belt is the part (being nondivisible in terms of operational conditions) which reliability indices depend on its structure, type, size, parameters, and size of the load material. It has been determined

*Corresponding author: Sly3@i.ua 
that probability of failure-free operation of the belt (up to its wear-out) $0.4-0.6$ corresponds to its service life within the range of 1.5-5 years depending on the conveyor length [7]. Results of the belt life optimization are represented in [8,9] depending upon the load pressure on the belt in a loading station as well as its abrasiveness. In this context, important factors effecting considerably the belt life and its wear within the linear section of a conveyor were not taken into consideration.

\section{Statement of the problem}

To solve the problem of the optimization of conveyor belt life, correlation dependences between the belt factors and parameters were studied; the obtained coefficients made it possible to select significant ones resulting in considerable effect upon the belt life. It was defined that they include granulometric composition of bulk load, its loading height, type of the applied loading devices, conveyor parameters, type and properties of the belt material, and physical and chemical properties of the load.

The obtained results have allowed to formulate a problem of the optimization of conveyor belt life in terms of its bulk loading: conveyor belt of $B_{b}$ width, $2 L$ length and $V_{b}$ velocity moves along the idlers; bulk material with diverse grain size composition is loaded at loading velocity $V_{l d}$ within the loading station, at distance $K_{2}$ from the idler. Granular material is loaded onto a belt continuously while lumps are loaded with the interval varying on a casual basis. Top cover of the belt is subject to constant wear within its central part and side rollers; wear intensity due to the effect of granular fractions within a loading station and conveyor flight is determined using following expressions:

$$
\begin{aligned}
& \Delta h_{\text {load }}=I_{l} \cdot S_{f_{l}} \psi ; \\
& \Delta h_{\text {lin }}=I_{\text {lin }} \cdot S_{f_{\text {lin }}} \psi \cdot l_{i} / l_{r},
\end{aligned}
$$

where $I_{l}, I_{\text {lin }}$ are linear intensity of belt wear within a loading station and on a conveyor flight respectively; $S_{f l}, S_{f l i n}$ are route of load friction against the belt within a loading station and on a linear section of a conveyor respectively; $\psi$ is coefficient taking into consideration load pressure on a belt; $l_{i} / l_{r}=n$ is number of idlers within section $l_{i}$ being subject to wear; and $l_{r}$ is spacing of idlers on a conveyor.

When belt is loaded with granular fractions, its wear mechanisms are similar within both loading station and linear section at the expense of sliding distance while load moving relative to a belt. It should be noted that within a loading station, load slides down the belt at the inclination angle of a conveyor; within the linear section, it slides along the generator line of a side roller under gravity in the process of load ascending and descending while passing the idlers. Wear of a conveyor belt depends considerably upon kinetic energy of the falling load that is transformed into friction work within the braking path:

$$
S_{b r}=\frac{\left(V_{b}-V_{l d}^{0}\right)^{2}}{2 g\left(f_{f r} \cos \beta-\sin \beta\right)},
$$

where $V_{l d}^{0}$ is projection of the velocity of falling load-belt interaction onto the belt motion plane; $f_{f r}$ is coefficient of load friction on a belt; and $\beta$ is angle of belt conveyor inclination.

While calculating belt wear due to the effect of granular fractions, we take the highest one of the two - within a loading point or within a linear section being equal to $\Delta h_{\max }$. Belt wear due to lumps coming from a loading device during operation time $t_{o}$ depends upon the amount of lumps $K_{i}$ contained within the total volume of bulk load on a casual basis. Lumps 
interact with a belt by means of granular load filling of $H_{l d}$ height. A layer of granular fractions $H_{l d}$ is loaded locally while maximum stresses are found within the contact area stipulated by a lump size. Each lump interacts with a belt within a loading station just once; in terms of linear section of a conveyor, the interaction takes place on each idler while its falling after lump-idler interaction. Paper [6] determines that conveyor belt wears out within a linear section of a conveyor owing to the load movement on a belt; that movement is generated under the effect when a belt with the load is pulled through the cross-section of idlers under the drive action. In this case, value of belt wear is determined similarly (3) taking into consideration the number of idlers and inclination angle of a conveyor:

$$
S_{l i n}=\frac{\left(V_{b}-V_{l d}^{0}\right)^{2} L}{2 g l_{r}\left(f_{f r} \cos \beta-\sin \beta\right)},
$$

where $V_{l d}^{0}$ is projection of the velocity of falling load-idle interaction onto the conveyor motion plane; and $L, l_{p}$ are conveyor length and spacing of idlers correspondingly.

We consider that load position on a belt experiences no changes after lump falling within a loading station; thus, it is possible to take following expression for belt wear:

$$
\Delta h=\Delta h_{l d}+\Delta h_{l i n},
$$

where $\Delta h_{l d}, \Delta h_{\text {lin }}$ are linear wear of the conveyor top cover within a loading station and linear section respectively.

Each lump-belt interaction is accompanied by the occurrence of a contact patch on the belt surface; value of stresses within that patch is determined from expression [10]:

$$
\sigma=\frac{2 P_{i n}}{\pi} \cdot \frac{\cos ^{4} \Theta}{H_{j}},
$$

where $P_{i n}=q m_{j} K_{d} \varphi$ are force of lump-belt interaction within a loading station or lumpidler interaction within a linear section; $q$ is linear load of granular fraction; $m_{j}$ is lump mass; $K_{d}$ is coefficient of dynamic interaction with a belt or idler; $\varphi$ is coefficient considering decrease of the interaction force owing to the material filling [7]; $H_{j}$ is height of granular fraction filling; and $\Theta$ is angle of stresses distribution within the area of lumpfilling contact; angle value was determined experimentally [10].

Value of angle $\Theta$ was determined experimentally under laboratory conditions. It is defined [4] that angle $\Theta$ varies from $15^{\circ}$ to $45^{\circ}$ in terms of lumps interaction within a loading station and from $2^{\circ}$ to $10^{\circ}$ on a conveyor flight while interacting with idlers. Maximum values of contact patch $\pi H^{2}{ }_{l d} \operatorname{tg}^{2} \Theta$ are $0.151 \mathrm{~m}^{2}$ within a loading station and $0.036 \mathrm{~m}^{2}$ within a conveyor flight.

It is taken in [6] that lumps interaction within a loading station is distributed over the central roller width according to the normal law; thus, after $n$ belt rotations, its surface will wear by value $\Delta h=\Delta h_{l d}+\Delta h_{l i n}$. Conveyor belt life up to the wear-out of its cover under the effect of bulk load will be as follows, taking into account $\Delta h_{\max }$ and $\Delta h$, [6]:

$$
T_{l}=\frac{\delta_{b}}{n_{h} \cdot\left(\Delta h_{\max }+\Delta h / n\right) t_{o}},
$$

where $\delta_{b}$ is thickness of working cover of a conveyor belt; $t_{o}$ is time of the conveyor onload operation; and $n_{h}=3600 V_{b} /(2 L)$ is the number of belt rotations per hour.

Analysis of expressions (3), (4), and (6) has shown that the expression in terms of the 
problem dealing with conveyor-belt life optimization may be selected in the following form:

$$
\Phi=\left(V_{b}-V_{l d}^{0}\right)^{2} \rightarrow \min .
$$

There are following limitations in the problem of conveyor-belt life optimization:

$$
\begin{gathered}
q_{\min }<q_{l d}<q_{\max } \\
0.1<f_{f r}<0.6 \\
1.0<H<5.0
\end{gathered}
$$

where $q_{\min }, q_{\max }$ are minimum and maximum possible linear loads; $f_{f r}$ is coefficient of load friction on a belt; and $H$ is loading height.

There are following varied parameters to be taken: $H$ is loading height; $l_{r}$ is idlers spacing шаг; $\gamma_{b}$ is angle of attack; $\beta$ is inclination angle of a conveyor; $V_{f}$ is feeder velocity; $D$ is diameter of a feeder drum; $V_{b}$ is belt velocity; $m_{l}$ is lump mass; $\varphi_{0}$ is angle of load separation from a feeder belt; and $q_{\min }, q_{\max }$ are minimum and maximum possible linear loads.

\section{Problem solution and its analysis}

A problem concerning optimization of conveyor belt life was solved numerically using equations (7), (8), and varied parameters. Two cases of belt conveyor loading were considered: direct-flow and with the help of loading devices with straight and curved troughs. In [11] represents a scheme of bulk load-conveyor belt interaction in general terms; the scheme means that cargo is loaded onto a belt in terms of velocity $V_{f}$ and initial angle of bulk load attack $\varphi_{0}$. In this case, lumpy load moves along a parabolic trajectory up to its interaction with a conveyor belt at angle of attack $\Theta$. In terms of horizontal conveyor $(\beta=0)$, angle of bulk load attack varies within the range of $25^{\circ}-30^{\circ}$ depending upon the loading height or parameters of a loading device and its configuration. If inclination angle of a conveyor changes up to $\beta_{\max }=12-14^{\circ}$, then angle of bulk load attack decreases; it may be represented in general terms as:

$$
\Theta=90-\left(\gamma_{t r}+\beta\right)
$$

where $\gamma_{t r}$ is angle of bulk load trajectory inclination relative to the horizontal.

When bulk load interacts with a conveyor belt, its wear is caused by considerable effect of the projection of horizontal component of absolute velocity of contact with a belt on the belt motion plane [6-8] (vertical component effects the stresses resulting in the loss of strength of the conveyor elements). While optimizing conveyor belt life, projection of the velocity of load-belt interaction onto the belt motion plane was determined using expressions [11]:

- for direct-flow loading within a loading station and within a linear section

$$
V_{l d}^{0}=V_{f}\left[\cos \beta \cos \left(\varphi_{0}-\psi\right)-\sin \beta \sin \left(\varphi_{0}-\psi\right)-g \Delta t \sin \beta\right]
$$

- for a loading device with a trough

$$
V_{l d}^{0}=\cos \gamma_{b} \sqrt{V_{0}^{2} \cos ^{2} \gamma_{b}+\left(V_{0} \sin \gamma_{b}+g \Delta t\right)^{2}}
$$

where $V_{f}, V_{0}$ are velocity of a feeder at the moment of load separation from a feeder belt 
or from a trough respectively; $\beta, \varphi_{0}, \gamma_{b}$ are inclination angle of a conveyor, angle of load separation from a feeder belt, and angle of belt attack with a load respectively; $g$ is acceleration of free fall; and $\Delta t$ is time of load falling onto a belt.

To determine projections of velocities (10) and (11), velocity of load separation from a feeder belt and trough should be determined depending upon the parameters of loading devices and trough configuration. Paper [6] determines theoretically and proves experimentally the angles and velocities of load separation from a feeder belt; in terms of loading devices, certain experimental studies have been performed which results are represented on Figure1 where $a$ is a straight trough profile and $b$ is a curved trough profile.

While selecting velocity for load to leave a feeder of loading device, it is considered that it depends upon the trough configuration: it is uniformly variable in terms of a straight trough; in terms of a curved trough, it is uniformly variable within a straight-line section and decelerated within a curvilinear one due to loss of energy for movement and friction forces (Fig. 1). Granular fractions of bulk loads reduce its transportation velocity owing to the expense of energy losses for movement which is taken into consideration by means of Chezy's velocity factor. In terms of bulk load consisting of separate portions of granular fractions and lumps being found within their volume and distributed on a casual basis, lumps move within a loading device trough faster than granular fractions; however, at specific trough areas, they decelerate, and, within the trough outlet, bulk load velocities become more equable $7.5 \mathrm{~m} / \mathrm{s}$ may be taken for a straight profile and $5.0 \mathrm{~m} / \mathrm{s}$ may be adopted for a curved profile (Fig. 1).
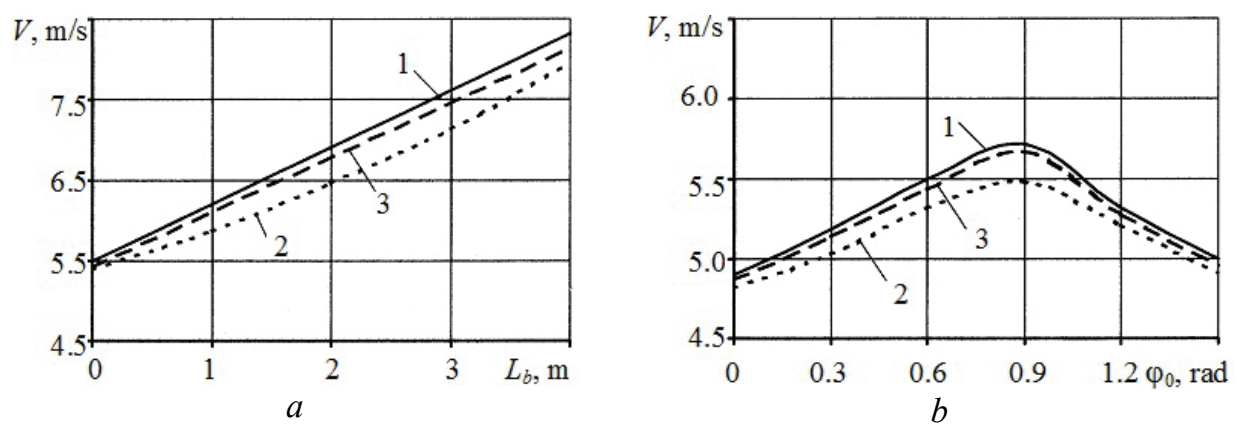

Fig. 1. Dependences of changes in load transportation velocity in a trough of a loading device: 1 - for separate lumps; 2 - for granular fractions; 3 - for lumpy load.

Figures 2 and 3 demonstrate dependences of values of the objective function upon different varied parameters. It has been determined that diameter of a feeder drum has practically no effect upon the objective function value (Fig. 3, a). If feeder velocity if from 0.2 to $1.2 \mathrm{~m} / \mathrm{s}$ for fixed angles of belt conveyor inclination (Fig. 3, b, curves 1, 2, 3, 4, and 5), then objective function is the minimum within the range of $0.6-0.8 \mathrm{~m} / \mathrm{s}$ and its value drops in terms of increasing feeder velocity and decreasing angle $\beta$. If inclination angle is $\beta=-16^{\circ}$, the objective function tends to zero.

Loading height is of dramatic impact upon the objective function value in terms of fixed inclination angles of a conveyor (Fig. 2). Minimum values of the objective function are possible, if loading height is from 0.5 up to $1.0 \mathrm{~m}$ within a loading station and if drop height is from 0.2 to $0.3 \mathrm{~m}$ on the linear section of a conveyor in terms of inclination angle of a conveyor being lower than zero (incline conveyors).

Thus, within a loading station, velocity of load sliding on a belt depends considerably upon the inclination angle of a conveyor, feeder velocity, and loading height; in terms of linear section, it depends on inclination angle of a conveyor, height of lump drop on granular fractions filling, and forces of their interaction. 


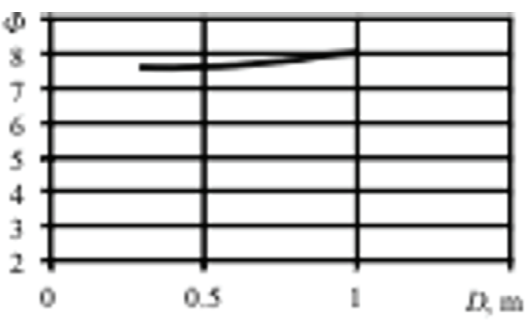

$a$

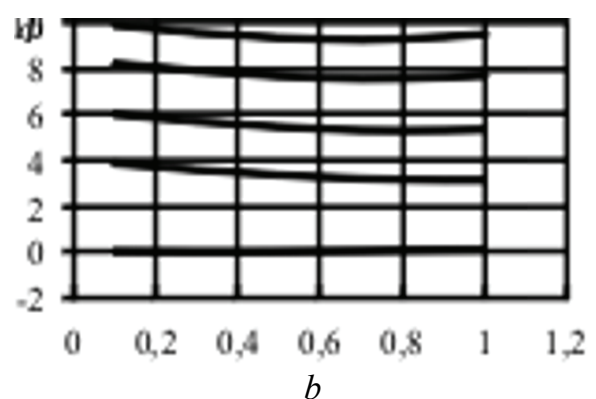

Fig. 2. Dependence of the value of objective function upon the feeder parameters: $a$ - upon the drum diameter; $b$ - upon the velocity of belt motion (curves 1,2, 3, 4, 5 for inclination angles of a conveyor being $-16^{\circ} ; 0^{\circ} ; 5^{\circ} ; 10^{\circ} ; 14^{\circ}$ respectively).

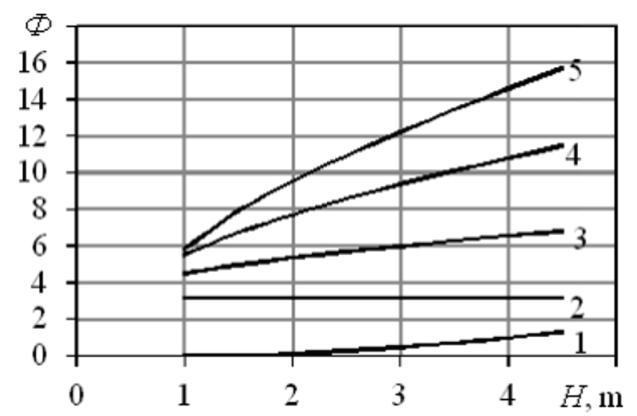

Fig. 3. Dependence of the value of objective function upon the height of load drop where curves 1, 2, $3,4,5$ correspond to inclination angles of a conveyor being $-16^{\circ} ; 0^{\circ} ; 5^{\circ} ; 10^{\circ} ; 14^{\circ}$.

Service life of conveyor belts was determined according to formula (6) taking into account (1)-(5) for following initial data: conveyor length from 200 to $600 \mathrm{~m}$, belt velocity is $2 \mathrm{~m} / \mathrm{s}$, inclination angle of a conveyor is from $-16^{\circ}$ up to $14^{\circ}$; cover thickness is $0.005 \mathrm{~m}$; and mass of lumps is from 40 to $80 \mathrm{~kg}$. Figure $4, \mathrm{a}, \mathrm{b}$ demonstrates regularities of changes in conveyor belt life depending upon the value of objective function, inclination angle of a conveyor, and conveyor length.
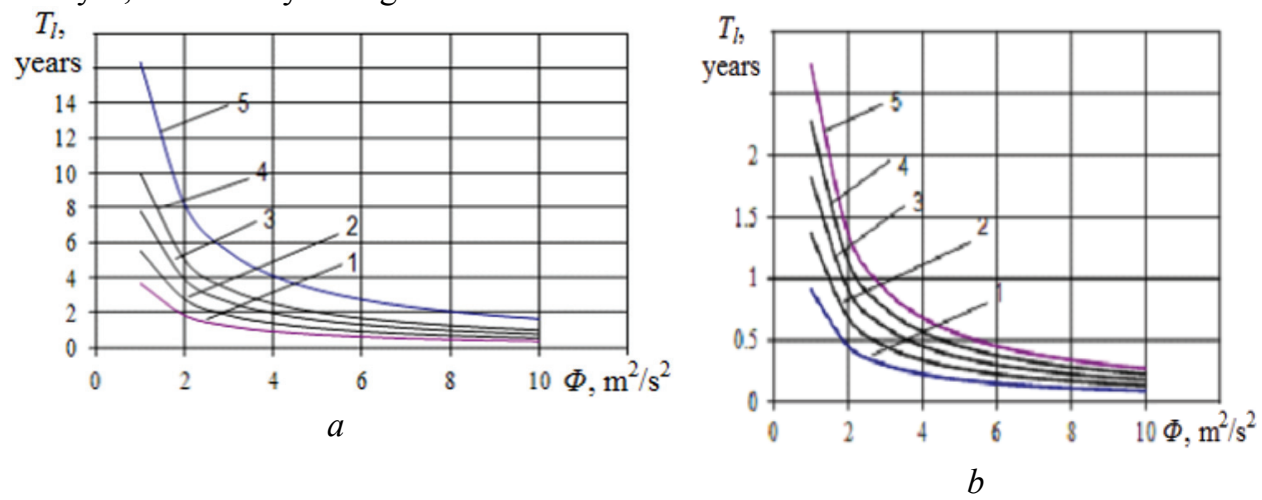

Fig. 4. Regularities of changes in conveyor belt life depending upon the value of objective function where $a$ - use of loading devices; $b$ - direct-flow loading; $1,2,3,4,5$ - conveyor length being 200; $300 ; 400 ; 500 ; 600 \mathrm{~m}$ correspondingly.

Comparative analysis of the conveyor belt life as for direct-flow loading (Fig. 4, b) and from the loading device trough (Fig. 4, a) was performed according to calculated data in 
terms of the parameter $\left(H, L_{b}, R_{l}, \varphi_{0}, \alpha, \beta, V_{0}, D\right)$ set searching. We considered that calculation variants, where belt life was maximum at minimum value of the objective function, were the best ones. It has been determined that use of loading devices with straight or curved trough profile makes it possible to increase service life of belts of short conveyors by $1.5-2$ times and the ones of long conveyors - by 4-5 times (Fig. 4,b, objective function is equal to 2) comparing to the direct-flow loading (Fig. 4,a). If inclination angle of a conveyor is up to $14^{\circ}$, inclination angle of the loading device trough is up to $60^{\circ}$, height of load drop onto a belt is from 0.5 to $1.0 \mathrm{~m}$ within a loading station and from 0.1 to 0.2 on a conveyor flight, and projection of load velocity on the belt motion plane calculated according to analytical expressions (10) and (11) involving regularities of Figure 1; then service life of belts for short conveyors increases by $20-30 \%$ while the one for long conveyors grows by $60-70 \%$.

\section{Conclusions}

A complex multiparameter problem concerning optimization of conveyor belt life in terms of loading its top cover with bulk load of different granulometric composition has been solved. It has been defined that the belt service life depends on various factors: load size, type of the involved loading devices, inclination angles of both conveyor and trough as well as difference of squared belt velocity and projection of horizontal component of the load onto the belt motion plane - objective function. Optimal (maximum) belt service life is reached in terms of value of the objective functions being close to $0.5-1.0 \mathrm{~m}^{2} / \mathrm{s}^{2}$.

\section{References}

1. Galkin, V.I., Dmitriev, V.G., Dyachenko, V.P. (2005). Sovremennaya teoriya lentochnykh konveyerov gornykh predpriyatiy. Moskva: MSMU

2. Monastyrsky, V. F., Monastyrskaya, N. N., Monastyrsky, S. V. (2003). Features of calculating loading devices during their interaction with bulk load, Proceedings of the symposium “Miner's Week - 2003”, MSMU, Moscow, February, 184-185

3. Zaostrovtsev, V.N., Mukhamedyanov, I.S., Monastyrsky, V. F. (2000). Practices of operating belt conveyors in terms of factory \#12 of Udachninsk mining and processing plant. Mining Journal, (7), 40-44

4. Ostrovsky, M.S., Radkevich, YA. M., Timeryazev, V.A. (2004). Criteria to control technical conditions of machines. Mining machines and automatics, (6), 40-42

5. Monastyrsky, V. F., Monastyrsky, S. V. (2004). Scientific substantiation of the initial data to determine consumer-oriented quality of the enterprises of ALROSA SC. Problems and prospects of complex development of cryolithozone mineral deposits, Proceedings of the International Scientific and Practical Conference, Yakutsk, 175-184

6. Monastyrsky, V.F. (1990). Development of methods and tools for managing the reliability of high-power belt conveyors. D. Sc. Thesis, Mining Machines, Institute of Geotechnical Mechanics named by N. Poljakov of National Academy of Sciences of Ukraine, Dnipropetrovsk, Ukraine

7. Polunin, V.T., Gulenko, G.N. (1986). Ekspluatatsiya moshchnykh konveyyerov. Moskva: Nedra

8. Kiriya, R.V. (2004). Optimization of the Parameters of Passive Shifting Knots of Belt Conveyers of Mining Enterprises. Ph. D. Thesis, Mining Machines, Institute of Geotechnical Mechanics named by N. Poljakov of National Academy of Sciences of Ukraine, Dnipropetrovsk, Ukraine

9. Kuksa, V.P. (1968). Studying earth movement within the transfer units of conveyor line. 
Ph. D. Thesis, Mining Machines, Kyiv, Ukraine

10. Timoshenko, S.P., Yang, D. KH. and Uiver, U. (1985). Kolebaniya v inzhenernom dele. Moskva: Fizmatlit

11. Monastyrsky, S.V. (2007). The Scientific Substantiation of Tape Conveyors Quality Adaptation to Various Conditions of Operation, Ph. D. Thesis, Mining Machines, Institute of Geotechnical Mechanics named by N. Poljakov of National Academy of Sciences of Ukraine, Dnipropetrovsk, Ukraine 